\title{
SMART FARMING
}

\section{Matthew N. O. Sadiku1*, Tolulope J. Ashaolu², Abayomi Ajayi-Majebi ${ }^{3}$ and Sarhan M. Musa1}

\author{
${ }^{1}$ Roy G. Perry College of Engineering, Prairie View A\&M University, Prairie View, TX, USA \\ ${ }^{2}$ College of Food Science, Southwest University, Tiansheng Road Beibei District, Chongqing, 400715, P.R. China \\ 32Department of Manufacturing Engineering, Central State University, P.O. Box 1004, Wilberforce, OH 45384-1004, USA
}

E-mail: sadiku@ieee.org; ashaolut@gmail.com; ajayi-majebi@centralstate.edu; smmusa@pvamu.edu

*Corresponding author details: Professor Matthew N. O. Sadiku, sadiku@ieee.org

\begin{abstract}
Smart farming refers to the adoption of information and communications technologies to enhance and automate agricultural processes and operations. It is a farming management concept that involves using modern technology to increase the quantity and quality of agricultural products. It makes the farming processes become increasingly data-driven and data-enabled. This paper provides a brief introduction to smart farming.
\end{abstract}

Keywords: smart farming; precision agriculture; ICT-based agriculture; digital agriculture

\section{INTRODUCTION}

Agriculture plays a significant role in the overall economic development of any nation since it provides us with indispensable resources such as food, medicine, and energy. It is the backbone of most developing economies [1]. For thousands of years, humans have been farming successfully, growing crops and raising livestock.

According to the United Nations Food and Agriculture Organization (FAO), the world needs to produce $70 \%$ more food in 2050 than it did in 2006. Smart farming addresses this challenge of feeding the ever increasing world population. It is a hi-tech, capital-intensive means of sustainably growing food for the masses. It basically integrates agronomy, human resource management, yield calculation, automation, warehousing, logistics, maintenance, and marketing into a single system [2].

Agriculture has witnessed several revolutions. The digitization of agriculture has resulted into precision agriculture and smart farming. This may influence employment opportunities and job profiles of farmers. Precision agriculture aims at optimizing the yield per unit farming land by using modern technologies such as GPS, sensors, robots, and big data.

It involves using predictive analytics to make smarter decisions in farming by collecting real-time data on weather, soil, crop maturity, equipment and labor costs. Smart farming refers to the adoption of information and communications technologies to enhance and automate agricultural processes and operations. Smart farming technologies cover all these aspects of precision agriculture. It applies to small (family farming) and complex family as well as organic farming.

\section{ENABLING TECHNOLOGIES}

Farmers use technologies such as mobile phones, robots, and computers along with tractors and hoes to produce more with less. They produce magical results that can transform the entire agriculture industry. The basic technologies for smart farming include precision equipment, the Internet of things (IoT), sensors and actuators, global positioning system (GPS), big data, unmanned aerial vehicles (UAVs, drones), and robotics. Some of these technologies are illustrated in Figure 1 [3] and explained below.

\section{- The Internet of Things}

The application of IoT in agriculture can have a great impact. IoT can address many challenges and increase the quality, quantity, and cost-effectiveness of agricultural production. The IoT is posed to push the future of farming to the next level. It will assist farmers in meeting the world's food demands in the coming years.

\section{- Sensor Network}

Although this is part of IoT technologies, it needs to be treated on its own. With the information and communications (IC) technologies, it is possible to create a sensor network that can be used for continuous monitoring of the farm [4]. Sensors placed in the farm are used in collecting information (such as soil moisture, fertilization, temperature, humidity, acidity, illumination) and providing farmers with real-time data on their land, crop, livestock, and equipment. Farmers can use data collected from remote sensors to decide where their water resources should be channeled. In 2001, John Deere, the world's largest agricultural equipment manufacturer, decided to fit their tractors and other machines with GPS sensors. Sensors attached to moving machinery can be used to take measurements on the run. Sensors can be placed inside cattle to measure stomach acidity and examine digestive problems.

\section{- Agricultural Automation}

Autonomous, robotic vehicles and artificial intelligence techniques have been developed at all levels of agricultural production such as mechanical weeding, applying fertilizer, or harvesting of crops. Drones and dronemounted cameras are used by farmers to survey their lands. GPS-guided tractors are becoming the norm. To get a synoptic view of their farm, some farmers employ satellites. these technical improvements constitute a revolution that will cause disruptive changes in agricultural practices. 


\section{CHALLENGES}

Technology that promises to improve a farm's production while lowering costs is appealing. Smart farming will make agriculture more profitable for farmers than conventional farming. It can also boost consumer acceptance since it enables increased product quality. However, the profound changes introduced by smart farming will come not only with opportunities but also great challenges. Several hurdles need to be overcome [4].

Some farmers have poor training in technology and are often skeptical of change since it can be painful and costly to get things wrong. Implementing smart farming technologies requires a lot of capital. The adoption of ICT will intensify the challenges of responsibility and accountability of new technologies. Limited knowledge and technical skills of individual farmers can be major hurdles particularly in developing nations. There is currently no single policy approach for achieving smart farming. A proactive development of policies for smart farming supporting the necessary legal and market architecture is necessary. For a smart farm to be fully automatic and factory-like, people would have to be cut out of the loop altogether. This requires introducing robots on the ground as well as in the air. Constant climate change, soil degradation, and water shortages are also hurdles that continue to increase in size with time. Small changes in these factors can have a major impact on profitability.

Smart farming raises some legal issues (such as data protection law and intellectual property or data ownership), which are not fully addressed. There is also a necessity to protect and safeguard data so that it does not get into the wrong hands.

\section{CONCLUSION}

Agriculture has seen a number of revolutions. It is undergoing a fourth revolution triggered by the exponentially increasing use of information and communications technologies (ICT) in agriculture. Smart farming is the adoption of ICT in order to enhance, monitor, and automate agricultural processes. It has a real potential to deliver a more productive and sustainable agriculture. If successful, smart farming can increase agricultural production, improve the competiveness of small farmers, and provide a growing urban population with fresher food. Smart farming is crucial to the future of agriculture. It will transform farmers' lives in both developed and developing nations.

\section{REFERENCES}

[1] C. Dwarkani et al., "Smart farming system using sensors for agricultural task automation," Proceedings of IEEE International Conference on Technological Innovations in ICT for Agriculture and Rural Development, 2015, pp. 4953.

[2] M. Schönfeld, R. Heil, and L. Bittner, "Big data on a farm-Smart farming," in T. Hoeren and B. KolanyRaiser (eds.), Big Data in Context, Springer, 2018, pp 109-120.

[3] "Toward smart farming: Agriculture embracing IoT vision,"https://www.google.com/search?q=smart $+\mathrm{f}$ arming\&tbm $=i$ sch\&tbo $=u \&$ source $=$ univ\&sa $=X \& v e d$ $=0$ ahUKEwjyku7_2oPaAhUs0YMKHVXXCTgQsAQIY g\&biw=2560\&bih=1283\#imgrc=1U_IXhGPXMMM:\&spf=1521851701360.
[4] A. Walter et al., "Opinion: Smart farming is key to developing sustainable agriculture," Proceedings of the National Academy of Sciences of the US A, vol. 114 , no. 24, 2017, pp. 6148-6150.

\section{AUTHORS}

Matthew N.o. Sadiku is a professor emeritus in the Department of Electrical and Computer Engineering at Prairie View A\&M University, Prairie View, Texas. He is the author of several books and papers. His areas of research interests include computational electromagnetics and computer networks. He is a fellow of IEEE.

Tolulope J. Ashaolu works at Southwest University. He is the author of several papers and two books. His research interests include functional foods and food microbiology.

Abayomi Ajayi-Majebi is a professor in the Department of Manufacturing Engineering at Central State University in Wilberforce, Ohio. In 2015 he was honored by the White House as a Champion of Change for his significant contributions to the engineering education of minority students. He is a senior member of both the Society of Manufacturing Engineers and the American Society for Quality.

Sarhan M. Musa is a professor in the Department of Electrical and Computer Engineering at Prairie View A\&M University, Prairie View, Texas. He has been the director of Prairie View Networking Academy, Texas, since 2004. He is an LTD Sprint and Boeing Welliver Fellow. His areas of research interests include computational electromagnetics and computer networks.

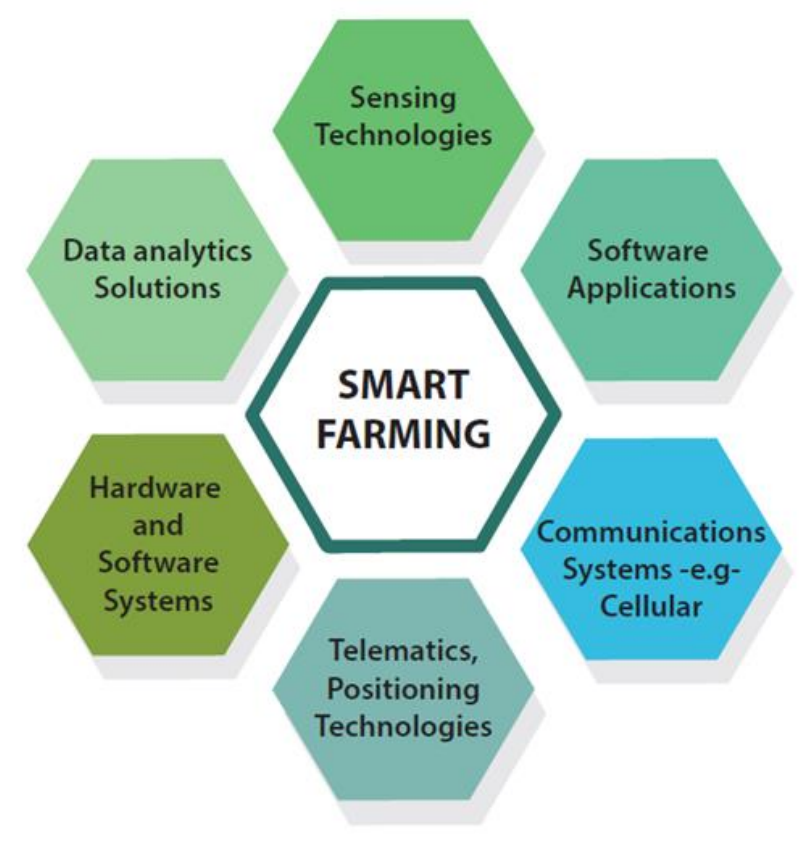

FIGURE 1: TECHNOLOGIES INVOLVED IN SMART FARMING [3]. 